\title{
Conhecimento político e virtudes públicas
}

\section{Political knowledge and public virtues}

\author{
Denis Coitinho Silveira \\ Universidade do Vale do Rio dos Sinos, Escola de Humanidades \\ deniscoitinhosilveira@gmail.com
}

\section{Resumo}

O objetivo do artigo é refletir sobre o escopo do conhecimento político a partir de uma contraposição ao argumento epistocrático defendido por Jason Brennan em Against Democracy. Para tal, início apresentando a concepção de conhecimento e ignorância de Brennan, bem como sua compreensão do que seja a política. Após, investigo o significado de conhecimento e ignorância a partir do ponto de vista da epistemologia das virtudes. $O$ passo seguinte será analisar a natureza mesma do domínio político. De posse disso, passo a considerar duas virtudes públicas, a saber, a prudência e a amizade cívica. Por fim, tematizo o fenômeno do progresso moral para mostrar que o tribalismo nem constitui a essência da natureza moral humana nem impossibilita o conhecimento político e que, assim, não teríamos uma razão conclusiva para defender a restrição da participação política.

Palavras-chave: Conhecimento político, ignorância, prudência, amizade cívica, progresso moral.

\section{Abstract}

The aim of this paper is to reflect on the scope of political knowledge from a counterpoint to the epistocratic argument defended by Jason Brennan in Against Democracy. To this end, I begin by presenting Brennan's conception of knowledge and ignorance is, as well his understanding of what politics is. Then, I will investigate the meaning of knowledge and ignorance from the virtue epistemology standpoint. The next step will be to analyze the very nature of the political domain. With this in mind, I will considerer two public virtues, namely, prudence and civic friendship. Finally, I will discuss the phenomenon of moral progress to show that tribalism is neither the essence of human moral nature nor does it preclude political knowledge and that, therefore, we would not have a conclusive reason to defend the restriction of political participation.

Keywords: Political knowledge, ignorance, prudence, civic friendship, moral progress. 


\section{I}

Jason Brennan, em Against Democracy, defende um argumento epistocrático, dizendo que a maioria dos eleitores contemporaneamente é ignorante em matéria de política, além de irracional, e que esta ignorância é causa de decisões incompetentes, injustas e ilegítimas e, assim, se deveria restringir o direito ao voto destes cidadãos politicamente ignorantes e implementar um tipo de epistocracia, dado que, em um sistema democrático, a escolha dos governantes é uma decisão política expressa por sufrágio universal (BRENNAN, 2017, p. 3-15). Seu ponto central é demonstrar que a maior parte dos cidadãos são ignorantes, apáticos e irracionais ou, em seus termos, são Hobbits ou Hooligans, decidindo politicamente de forma tribalista, o que colocaria em xeque a legitimidade do próprio sistema democrático (BRENNAN, 2017, p. 3-8). Ele defende uma tese condicional, dizendo que se a epistocracia for melhor que a democracia, então, devemos implementá-la, sendo um sistema político epistocrático o que distribui o poder na proporção do conhecimento ou competência. Este tipo de epistocracia é formulada a partir de um princípio antiautoritário, que diz que:

Quando alguns cidadãos são moralmente irrazoáveis, ignorantes ou incompetentes sobre política, isto justifica não permitir a eles o exercício da autoridade política sobre os outros. Isto justifica, também, proibi-los de ter poder ou reduzir o seu poder de forma a proteger as pessoas inocentes de sua incompetência (BRENNAN, 2017, p. 17).

Isto parece implicar que a restrição ao sufrágio universal se dará com base no critério epistêmico de ignorância sobre os assuntos políticos. $O$ problema é que Brennan não esclarece detalhadamente o que seria o conhecimento e a ignorância, bem como não diz muito sobre o próprio domínio político. A despeito de ser tentador defender a democracia contra a epistocracia, meu objetivo aqui será mais modesto. Apenas investigo o que seja o conhecimento político, bem como a ignorância nessa esfera, além de buscar refletir sobre o que constitui a especificidade do político. Isto parece importante porque não pareceria justo restringir o voto de certas pessoas com base em um critério tão complexo quanto o de ignorância, de forma a parecer arbitrária a distinção entre o que sabe e $\circ$ que ignora, o mesmo se dando em razão da 
especificidade da esfera política, sobretudo porque, em geral, as pessoas que teriam este tipo de restrição ao voto seriam as mais desfavorecidas socialmente, tais como pobres, negros, latinos e mulheres. Mas, vejamos.

Em primeiro lugar, Brennan não problematiza o que seja conhecimento e ignorância. No capítulo 2 da referida obra, exemplifica o que os cidadãos não sabem: em anos eleitorais, a maioria dos cidadãos não consegue identificar nenhum candidato ao Congresso em seu distrito; os cidadãos geralmente não sabem que partido controla - Congresso; os americanos sobre-estimam quanto dinheiro é gasto em ajuda internacional etc. (BRENNAN, 2017, p. 25-30). Esses exemplos já mostram que ele está tomando o conhecimento como equivalente a possuir informações no campo da política, da história, da sociologia e mesmo da economia, entre outros campos correlatos. Mas, será mesmo que conhecimento pode ser equivalente a apenas possuir certas informações? Também, ele parece tratar do conhecimento como de tudo ou nada e não como uma questão de graus. Ou se teria o conhecimento político ou se seria ignorante, como no caso de se ter um conhecimento político-jurídico para saber que a política dos EUA relativa à guerra às drogas é contraproducente e particularmente prejudicial às minorias ou de se ter um conhecimento médico que pode salvar a vida de alguém que está se engasgando (BRENNAN, 2017, p. 117, 122).

Essa perspectiva transmite a ideia de que alguns cidadãos teriam melhores juízos políticos que outros e que existiriam fatos políticos facilmente identificados. $O$ conhecimento político, assim, seria similar ao conhecimento científico por estar relacionado com as evidências. Dessa forma, não é muito difícil identificar que ele esteja tomando o conhecimento de forma tradicional, isto é, como sinônimo de crença verdadeira justificada, bem como a ignorância seria ter crenças falsas, como no caso de alguém que toma uma decisão política sem levar em conta as evidências, apenas julgando através de seus preconceitos tribalistas. Argumentarei que o conhecimento parece ser muito mais complexo do que Brennan supõe.

Em segundo lugar, Brennan não esclarece o que seja o domínio do político. Ele diz que a política não é um poema, isto significando um distanciamento de uma visão romântica, em que ela teria o papel de juntar-nos, educar-nos e civilizar-nos e possibilitar a amizade entre os concidadãos e bons princípios cívicos. A política, para ele, faz o oposto, a saber: separa-nos, paralisa-nos, corrompe-nos (BRENNAN, 2017, p. xv). Isso implica uma visão instrumentalista da política, em que ela é interpretada a 
partir de sua função, sendo mais bem concebida como um martelo (instrumento), que tem, então, apenas a função de possibilitar o bem-estar dos agentes. Por isso, devemos escolher o regime político que oportuniza os melhores resultados, traz mais justiça, elimina a pobreza, termina as guerras e garante a segurança da população. Para Brennan, a participação política tende a nos a corromper ao invés de desenvolver o caráter moral e intelectual dos cidadãos, sendo que esta participação e as liberdades políticas têm apenas um valor instrumental e não intrínseco e, por isso, se produziria um resultado político mais justo se substituirmos a democracia por algum tipo de epistocracia (BRENNAN, 2017, p. 18-19). Ele toma a política como uma técnica; também, como uma atividade de controle sobre a vida das pessoas e como um jogo de soma zero, em que a vitória de um significará obrigatoriamente a derrota de outro (BRENNAN, 2017, p. 124-132).

Essa visão instrumentalista parece reduzir a política apenas ao processo de disputa pelo poder, especialmente reduzindo a política às eleições, bem como parece não reconhecer o valor representativo e simbólico de uma escolha neste domínio. Por mais que os eleitores decidam e votem a partir dos vieses cognitivos, sobretudo, de tribalismo e confirmação, como veremos a seguir, não se pode deixar de reconhecer que as pessoas dão valor às suas escolhas, uma vez que se tomam como autônomas e responsáveis e uma restrição neste campo poderia implicar uma perda de autoestima, além de uma modificação em certas práticas sociais, tal como as eleições como as conhecemos. Também, é importante reconhecer, que para além da disputa eleitoral, a política parece ter relação com a tentativa de encontrar soluções negociadas para os conflitos humanos. Como interpretar a criação da Organização das Nações Unidas (ONU) e a proclamação da Declaração Universal dos Direitos Humanos senão a partir dessa característica?

Dito isto, meu objetivo será refletir sobre o escopo do conhecimento político. Inicio investigando o que é conhecimento e ignorância a partir da epistemologia das virtudes. Após, busco esclarecer a natureza mesma do político. De posse disso, abordo duas virtudes públicas centrais, a saber, a prudência e a amizade cívica. Por fim, tematizo o fenômeno do progresso moral para mostrar que as disfunções cognitivas não impossibilitam o conhecimento neste campo; apenas o tornam mais difícil. 
II

Como Jason Brennan, em Against Democracy, não problematiza o que seria o conhecimento e a ignorância e, considerando os exemplos utilizados, podemos postular que ele está tomando o conhecimento ou a competência neste campo de forma tradicional, como equivalente a ter uma crença verdadeira e justificada ou, como afirmado por Chisholm, como tendo uma crença verdadeira assegurada com uma evidência adequada (CHISLOM, 1957, p. 54-66). E, similarmente, a ignorância seria ausência de conhecimento ou ter uma crença falsa em razão das evidências inadequadas. $E$ isso parece importante porque para Brennan um dos problemas centrais da política é que as pessoas tendem a ignorar as evidências, decidindo tribalisticamente, isto é, através de preconceitos intergrupais, ou influenciadas pelo viés da confirmação, apenas aceitando as evidências que apoiam o seu próprio ponto de vista ${ }^{1}$.

Vejamos um exemplo de ignorância e conhecimento político dado por Brennan. Para ele, os votantes dos EUA tendem a ignorar os efeitos da guerra às drogas para as minorias, de forma que tomar medidas duras contra o crime tende a causar mais prejuízo para os pobres, negros e latinos. E, assim, seria mais provável que um votante epistocrático soubesse que esta política relativa ao crime e às drogas é contraproducente (BRENNAN, 2017, p. 117). Com isso, teríamos certas evidências, como a constatação de que a maior parte das pessoas presas são pobres, negros e latinos e que estão presas por tráfico/consumo de drogas e que insistir na política de guerra às drogas apenas aumentaria a população carcerária com os membros destas minorias. O problema é que a pura constatação dessas evidências não nos mostra automaticamente qual a política que deveria ser colocada em seu lugar. Por exemplo, deveríamos apenas descriminalizar o consumo de drogas ou deveríamos, ainda,

\footnotetext{
1 Brennan faz referência a um conjunto significativo de vieses cognitivos que parecem influenciar negativamente as decisões políticas: (i) Tribalismo político: tendência a desenvolver animosidade em relação aos grupos rivais e rejeitar tudo que vem deles. Viés da confirmação: tendência em aceitar as evidências que comprovam nosso ponto de vista e ignorar todas as que se contrapõem a ele. Viés da disponibilidade: tendência de erro em estimar probabilidades. Contágio afetivo: tendência em ignorar os dados em razão das emoções. Efeitos de enquadramento: tendência em avaliar as informações a partir de como elas são apresentadas. Pressão dos pares e autoridade: tendência em sujeitar nossa opinião à da maioria e em aceitar o testemunho das pessoas com autoridade (BRENNAN, 2017, p. 39-48).
} 
legalizar certas drogas? E qual garantia desta política alternativa não causar problemas à saúde da população? Mesmo quando estamos falando do conhecimento do mundo externo, ter evidências adequadas não implica automaticamente em conhecimento, como bem nos aponta Gettier; mas no campo político, é ainda mais complexo.

Em seu já clássico artigo de 1963, Edmund Gettier apresenta dois casos para mostrar que se pode chegar a uma crença verdadeira e justificada aleatoriamente, isto é, por sorte. A posição tradicional defende as seguintes condições para o conhecimento: (a) $S$ sabe que $P$ sse (i) $P$ é verdadeira, (ii) $S$ acredita que $P$, e (iii) $S$ está justificado em acreditar que $P$. Ou, segundo Chisholm: (b) $S$ sabe que $P$ sse (i) $S$ aceita $P$, (ii) $S$ tem evidência adequada para $P$, e (iii) $P$ é verdadeira. Ou, ainda, segundo Ayer: (c) $S$ sabe que $\mathrm{P}$ sse (i) $\mathrm{P}$ é verdadeiro, (ii) $\mathrm{S}$ está seguro que $\mathrm{P}$ é verdadeiro, e (iii) $\mathrm{S}$ tem o direito de estar seguro que $P$ é verdadeiro. $O$ ponto de Gettier é mostrar que estas condições não são suficientes para se obter conhecimento. Vejamos o primeiro caso. Suponha-se que Smith e Jones tenham se candidatado a um certo emprego. E suponha-se que Smith tem fortes provas a favor da seguinte proposição conjuntiva: (d) Jones é o homem que vai conseguir o emprego, e Jones tem dez moedas no bolso. As evidências que Smith tem a favor de $d$ podem ser que o presidente da companhia lhe tenha assegurado que no fim Jones seria o selecionado e que ele, Smith, tenha contado as moedas do bolso de Jones há dez minutos. A proposição $d$ implica em (e) 0 homem que vai ficar com o emprego tem dez moedas no bolso. Suponha-se que Smith vê que (d) implica (e) e que aceita (e) com base em (d), a favor da qual ele tem fortes provas. Neste caso, Smith está claramente justificado em acreditar que (e) é verdadeira. Mas imagine-se que, além disso, sem Smith o saber, é ele e não Jones que vai ficar com o emprego. Imagine-se também que, sem o saber, ele próprio tem dez moedas no bolso. Assim, a proposição (e) é verdadeira, apesar de a proposição (d) ser falsa (GETTIER, 1963, p. 121-122).

A partir desse exemplo, podemos reconhecer que "estar justificado em acreditar em P" ou "ter a evidência adequada para P" ou "estar seguro apropriadamente" não pode contar como condições suficientes para assegurar a verdade das proposições e, assim, o conhecimento poderia ser interpretado em uma perspectiva mais falibilista, de forma que a probabilidade e mesmo a disposição dos agentes e sua regularidade poderiam exercer um papel relevante, sobretudo ao pensarmos na esfera política que deve levar em conta, ainda, as emoções no processo de decisão. Por essa razão, a 
epistemologia das virtudes parece mais adequada para os nossos propósitos de tematizar o conhecimento político, uma vez que ela não compreende o conhecimento como uma crença verdadeira justificada, mas como um tipo de performance em que se é bem-sucedido. Ernest Sosa, em A Virtue Epistemology: Apt Belief and Reflexive Knowledge, sustenta que o conhecimento deve ser visto como algo que é resultado das virtudes intelectuais de um agente, tendo por foco as habilidades e o caráter. Para ele, o conhecimento é um tipo de performance bem-sucedida, sendo que esta performance é um tipo de ação que visa a verdade. Se obtém conhecimento, então, se a performance do agente for apta, significando ver o conhecimento como resultado das competências do agente ou como resultado de suas virtudes. Dessa forma, uma performance será apta quando ela for bem-sucedida, isto é, quando ela alcançar o alvo, além de poder ser suficientemente atribuída à competência do agente. $O$ exemplo do arqueiro que lança sua flecha em busca do alvo é bastante ilustrativo, uma vez que, ele tendo habilidade, não será uma questão de sorte acertar 0 alvo. $O$ arqueiro acerta 0 alvo por causa de sua aptidão e acertar o alvo significa agir para chegar a uma crença bem-sucedida reflexivamente (SOSA, 2007, p. 22-23).

$O$ interessante neste modelo alternativo é a possibilidade de ver o conhecimento como uma expressão de certas virtudes intelectuais, como a prudência, por exemplo, que é a disposição para encontrar os meios adequados para realizar um fim que é bom, sendo as virtudes conquistadas com exercício através de um processo de habituação. $E$ a virtude pode ser compreendida como uma disposição estável do caráter do agente, sendo uma tendência da pessoa ser de uma certa forma, pois a virtude é a marca do seu caráter. Esta disposição, que é ativa, requer habituação e experiência. Julia Annas, em Intelligente Virtue, diz que esta disposição não pode ser vista como uma rotina, em razão de precisar de um constante monitoramento para o aperfeiçoamento e, dessa forma, a virtude seria uma disposição de caráter que permite uma resposta criativa e imaginativa aos novos desafios (ANNAS, 2011, p. 14). Aliás, Annas também estabelece uma interessante analogia entre virtude e habilidade prática, como a de tocar piano. Assim, se adquire uma virtude, por exemplo, a prudência, praticando atos prudentes, da mesma forma que se adquire a habilidade de tocar piano através do exercício repetido (ANNAS, 2011, p. 1-7). E de posse dessa virtude, o agente parece estar em melhores condições para realizar uma performance bem-sucedida, acertando o alvo. Lembrando nosso exemplo de guerra às drogas, alguém prudente poderia levar em conta, também, 
a possibilidade de que o fim desta política possa ser ainda mais nocivo à sociedade e, assim, a descriminalização poderia ser vista como superior à plena legalização.

Mas, veja-se que uma situação de incerteza sobre qual política adotar parece ser constitutivo da prática do agente prudente que deve imaginar muitos cenários alternativos antes de decidir, mas sem ter a garantia que sua escolha realmente será a melhor e, assim, se pode notar que uma situação de incerteza pode ser interpretada como um tipo de ignorância. $O$ curioso é que este fenômeno é geralmente interpretado como ausência de conhecimento e, posto que o conhecimento tradicionalmente seria chegar a uma crença verdadeira justificada ou assegurada por evidências adequadas, a ignorância seria ter uma crença falsa, como no caso de defender o aumento da punição como forma de reduzir o problema da criminalidade e alcançar a segurança. Ainda de um ponto de vista tradicional, o agente prudente, o que tem sabedoria prática, seria tomado como paradigma daquele que sabe e não como um exemplo daquele que ignora. Mas, entendendo melhor o critério da virtude, ter prudência pode ser visto como ter um tipo de conhecimento dos meios necessários para realizar o fim bom que está circunscrito por uma situação de diversidade e incerteza ${ }^{2}$.

Tomando a perspectiva da epistemologia das virtudes, a ignorância seria melhor compreendida como um estado em que o agente usaria crenças malsucedidas como fundamento de suas decisões políticas, por exemplo, podendo ser entendida, também, como um estado de ausência de certas virtudes. A vantagem dessa perspectiva epistemológica é sua inclusividade, pois a ignorância, assim, além de ser tratada como equivalente a assegurar uma crença falsa, pode ser tomada como a defesa de uma crença malsucedida, a suspensão do juízo, a ausência de consideração sobre um dado tema ou, até mesmo, uma situação de incerteza. ${ }^{3}$ Assim, um agente prudente seria aquele que adquire a sabedoria política fazendo escolhas a partir do processo de pesar razões, escolhas estas que podem ser certas ou erradas, sendo melhor interpretada como um "saber como" do que como um "saber que", isto é, como um saber prático ao

\footnotetext{
${ }^{2}$ Aristóteles diz na Ethica Nicomachea que a ciência política, que inclui a ética e a política, é um tipo de conhecimento cercado por diversidade de opiniões e incertezas sobre o bom e o justo, mas que pode auxiliar os indivíduos a melhor decidir em casos complexos e agir de forma apropriada, que seria a virtuosa, em razão dela indicar a verdade de forma aproximada e em linhas gerais, estando esse conhecimento ligado intrinsecamente à experiência dos agentes e a sua disposição em agir virtuosamente (ARISTOTLE, 1999, 1094b12-20).

${ }^{3}$ Rik Peels define a ignorância como uma atitude mental em relação a uma crença verdadeira, podendo ser vista como (i) ter uma crença falsa, (ii) suspender o juízo sobre uma proposição verdadeira, (iii) não ter ideia sobre a proposição verdadeira ou (iv) estar incerto. Esta posição de Peels é mais inclusiva e parece capturar melhor o que está envolvido no fenômeno da ignorância. Ver Peels, 2010, p. 62-64.
} 
invés de proposicional. $E$, assim, a conquista da virtude seria uma prática, um processo de saída da ignorância para o conhecimento numa dimensão de graus e não de tudo ou nada.

A partir desta problematização do significado do conhecimento e ignorância, gostaria de apontar para um certo perigo na proposta de Brennan. Sendo a ignorância política uma razão para a exclusão do direito ao voto, e sendo a ignorância a ausência de conhecimento, isto é, o ter crenças falsas, então, todos poderiam ser excluídos deste direito e isso porque é difícil saber o que seja conhecimento neste domínio. Por exemplo, o que defende a política de guerra às drogas seria ignorante, logo, ele deveria ter seu direito ao voto restringido. Em contraposição, defender a descriminalização das drogas ou a sua legalização seria exemplo de conhecimento político. Mas, como distinguir o que conta como ignorância e como sabedoria em um domínio cercado de diversidade de opiniões e incerteza? Esta distinção não poderia ser arbitrária? E considerando que sempre julgamos a partir de vieses cognitivos e a partir de nossas próprias experiências, não é difícil imaginar um cenário em que esta seria claramente arbitrária. Por exemplo, imaginemos alguém que defende uma política econômica keynesiana como forma de obter prosperidade e outro que defende uma política neoliberal fortemente privatista. Quem decidiria o que conta como conhecimento e ignorância? Seguindo a sugestão de Brennan, deveríamos restringir o direito de voto dos ignorantes, mas pode ser o caso apenas de termos uma diferença de opiniões e, assim, seria arbitrário só restringir certas crenças e não outras.

Também, esta proposta pode ser vista como injusta se levarmos em conta que as condições para se alcançar o conhecimento político não são simétricas em sociedades com grande desigualdade econômica. Nas pesquisas usadas por Brennan, são os pobres, negros, latinos e mulheres que demonstram ter maior ignorância política, enquanto os homens, brancos, ricos e escolarizados demostram ter maior conhecimento neste campo (BRENNAN, 2017, p. 32-33). E por que isto? Provavelmente porque estes grupos vulneráveis não tiveram um ambiente rico cognitivamente, isto é, não tiveram boa escola, tempo para estudar e acesso à cultura etc. Não parece justo, então, restringir o direito de voto destas minorias em razão destas condições assimétricas serem involuntárias. Ao contrário, o mais justo seria modificar a organização social de maneira a oferecer condições equitativas para todos em relação ao ambiente cognitivo. 
III

Agora, qual a especificidade do domínio político para Brennan? Ele afirma que a política não é um poema, isto significando tomá-la instrumentalmente, isto é, tendo o seu valor medido por seu resultado, sem valor intrínseco e, por esse motivo, se deveria preferir a epistocracia à democracia em razão de parecer superior na garantia do bemestar dos cidadãos. Esta é uma perspectiva claramente não ideal, uma vez que busca refletir quais instituições seriam melhores considerando como são as pessoas reais ao invés de interrogar quais seriam as melhores instituições se todas as pessoas fossem racionais e morais. A pergunta feita por Brennan é como deveríamos pensar a participação política e o poder considerando as falhas morais e intelectuais dos agentes (BRENNAN, 2017, p. 19). Mas, ele não esclarece o que seria mesmo a "política".

Como ele está fazendo uso de uma teoria não ideal, se presume que ele esteja assumindo um realismo político ao tomar como ponto de partida o como as pessoas são "realmente", o que parece relacionado com um certo ceticismo sobre as capacidades morais e intelectuais dos agentes, além de estar tomando a política como uma técnica, podendo ser melhor compreendida enquanto gestão, sendo o conhecimento político o mesmo que ter informações relevantes para subsidiar a tomada de decisões. Com isso e, também, em razão dos exemplos dados, a política parece estar sendo comparada à ciência, uma vez que Brennan afirma que a maior parte dos eleitores seriam ignorantes e irracionais sobre os fatos políticos, o que significaria tomar decisões com base em evidências inadequadas. Ele diz, por exemplo, citando Caplan, que os votantes têm pouco conhecimento sociológico, histórico, de ciência política e, sobretudo, pouco conhecimento econômico. Diz que o votante comum americano não sabe que o livre mercado como postulado por Adam Smith é superior ao mercantilismo (BRENNAN, 2017, p. 29). Assim, uma decisão política sábia seria a subsidiada pela informação adequada e pelo conjunto de teorias sociais relevantes para identificar as evidências relevantes. Mas será mesmo que uma escolha política pode ser reduzida à identificação de evidências factuais? Seria a política equivalente à ciência?

Importante notar que se a escolha se referir a qual o sistema econômico é mais eficiente, o livre mercado ou o mercantilismo, eu posso concordar que há evidências suficientes que provam a superioridade do livre mercado. Agora, se a escolha, por 
exemplo, for entre o livre mercado per se e o livre mercado com alguma regulação por parte do Estado, como para evitar monopólios, então, já não ficaria tão claro assim quais seriam as evidências relevantes ou os fatos que um experto reconheceria tão facilmente. Veja que economistas treinados tendem a divergir a esse respeito. Isso para não mencionar a divergência entre os que apoiam uma política econômica de bem-estar social e os que defendem uma política econômica de Estado mínimo. Novamente, quais os fatos ou evidências relevantes que deveriam ser reconhecidos pelo experto? Se essa divergência é encontrada entre economistas, isto é, cientistas, o que dizer dos votantes comuns?

Para além desta visão reducionista, a saber, que interpreta a decisão política como uma identificação neutra de certos fatos reconhecidos pelo votante epistocrático, a escolha no campo político parece revelar duas questões significativas: que o valor da escolha não é apenas instrumental, uma vez que ela revela quem se é, sendo essa escolha também simbólica e que trata-se de deliberar e decidir entre razões das quais temos dúvidas ou mesmo discordância em um espaço público. $E$ isto parece nos mostrar que o domínio político tem diferenças importantes da esfera científica, uma vez que o tipo de certeza e clareza que podemos obter nestes dois campos é bastante distinto. Mas, vejamos isso mais detalhadamente.

Em primeiro lugar, é importante refletir sobre o valor da escolha. Em nossas práticas sociais, escolhemos a todo momento. Escolhemos quem serão nossos amigos, com quem vamos namorar e casar, que profissão seguir, que filme assistir e, também, qual candidato de certo partido político eleger. Também, que só vemos como justa uma punição considerando que o agente que infringiu uma certa lei pôde escolher. Assim, a pergunta relevante é saber se essas escolhas que pervadem nossas vidas poderiam ser tomadas como simplesmente instrumentais, isto é, como tendo seu valor pelo resultado que oportunizam? Penso que não, uma vez que estas escolhas parecem simbolizar nossa autonomia, isto é, nossa capacidade de não sermos heterorregulados, e a ideia de autonomia parece central na constituição de nossas vidas tanto pessoal como social. Imaginem uma sociedade em que o Estado determina qual profissão cada agente deve seguir, bem como com quem ele deve casar. Mesmo considerando que os resultados sejam favoráveis, no sentido de haver menos divórcios e maior produtividade, não vejo possibilidade de fácil aceitação pelos agentes e isso porque valoramos nossa presumida capacidade de escolha e construímos uma ordem social com base nessa pressuposição. 
Seria diferente ao considerar apenas a escolha política? Creio que não e isso porque até mesmo uma escolha em um candidato numa eleição revela quem se é e quais valores de fato importam.

Sobre este ponto, Nozick diz corretamente que o poder político expresso através do voto simboliza nossa dignidade humana igual e nossa autonomia. Destaca que nossas escolhas políticas, representadas pelo voto, não seriam importantes apenas para direcionar o poder do governo para certas áreas como saúde, educação ou economia, entre outras. Além disso, elas seriam importantes por simbolizar nossa capacidade de autodirecionamento, isto é, nossa capacidade de direcionar nossas ações e decisões sem interferência externa. Com isso em mente, até mesmo nossas opiniões políticas deveriam ter igual peso, sob o perigo de perdermos nosso estatuto de seres autônomos. E, que tipo de sociedade teríamos se perdêssemos este estatuto de seres autorregulados, isto é, se não nos reconhecêssemos mais como autogovernados? ${ }^{4}$

Em segundo lugar, é importante reconhecer uma especificidade da politica que é a pluralidade, isto é, que há divergências entre as visões de mundo dos cidadãos e não somente ignorância e irracionalidade na escolha das políticas ou mesmo dos candidatos. Em "The Domain of the Political and Overlapping Consensus" (1989), John Rawls faz uma interessante reflexão sobre o que propriamente constituiria a esfera política. Para ele, existem cinco fatos gerais deste domínio que deveriam ser reconhecidos por todos. O primeiro é o fato do pluralismo, que nos diz que a diversidade de doutrinas abrangentes (religiosas, morais e filosóficas) não é uma contingência histórica, mas um traço permanente da cultura pública das democracias contemporâneas. O segundo é o fato da opressão, que nos mostra que somente o poder tirânico estatal poderia manter uma adesão duradoura a uma doutrina abrangente única, o que pode ser exemplificado com a instituição da Inquisição no medievo. $O$ terceiro fato nos informa que um regime democrático duradouro precisa ter apoio livre de uma maioria substancial dos cidadãos politicamente ativos, não estando dividido por doutrinas antagônicas e por classes sociais hostis umas às outras. O quarto fato nos aponta que a cultura pública de uma sociedade democrática relativamente estável contém certas ideias intuitivas que podem ser base para formular uma concepção política de justiça. E o quinto fato tem relação com os limites da razão, que

\footnotetext{
${ }^{4}$ Nas palavras de Nozick, "Votamos (...) em parte como expressão e afirmação simbólica do nosso estatuto como seres autônomos e autogovernados, cujos juízos ponderados ou mesmo opiniões devem ter igual peso que os dos outros" (NOZICK, 1990, p. 286).
} 
nos mostra que emitimos vários dos nossos mais importantes juízos em condições tais que se torna improvável que pessoas racionais e razoáveis cheguem sempre às mesmas conclusões após um debate livre (RAWLS, 1999, p. 474-475, 478). E, mais importante, quando analisa as características da política, ressalta que a relação política se dá entre os que vivem em uma sociedade, na qual ingressam ao nascer e só saem ao morrer, o que implica uma diferença do campo associativo, que é voluntário, bem como difere do campo familiar e pessoal, que são afetivos num sentido estranho à política. Em síntese, a política se dá no espaço público que é involuntário, não podendo ser reduzida à esfera privada (RAWLS, 1999, p. 482-484).

Ao invés de pensar no domínio político como sendo constituído por certos fatos que deveriam ser reconhecidos pelo experto, Rawls o interpreta a partir do paradigma do pluralismo razoável. Essa compreensão de política nos leva a tomar os desacordos não como faz Brennan, como expressão de preconceitos, interesses pessoais e grupais, cegueira, teimosia, irracionalidade, burrice, pois isso seria o mesmo que questionar a boa-fé dos que discordam de nós, mas como ligados à complexidade das provas empíricas, ao peso relativo sobre o tipo de consideração que é pertinente, à indeterminação e vagueza dos conceitos, bem como à influência de nossa experiência de vida na consideração de certos valores e de certas provas ${ }^{5}$.

Essa compreensão das fontes do desacordo é relevante, pois mostra a complexidade da política. Por exemplo, para Brennan, haveria evidências relevantes que devem ser identificadas por aquele que tem conhecimento e $\circ$ não reconhecimento destas evidências seria sinônimo de ignorância. Para Rawls, alternativamente, as evidências empíricas que sustentam um caso são complexas e podem ser interpretadas de várias formas. Por exemplo, podemos atribuir peso relativo diferente às evidências e, assim, chegar a diferentes conclusões. Também, nossas experiências pessoais parecem influenciar fortemente a forma com que avaliamos uma evidência e os valores envolvidos. Imaginem a discussão entre um agente que defende uma política de bemestar social e, especialmente, políticas de ações afirmativas, e outro agente que defende

\footnotetext{
${ }^{5}$ Para Rawls, as fontes do desacordo são: (i) a prova empírica que sustenta o caso pode ser contraditória e complexa; (ii) podemos divergir no tocante ao peso relativo sobre o tipo de consideração que é pertinente e, assim, chegar a julgamentos diferentes; (iii) todos os nossos conceitos, de certa forma, são vagos e indeterminados, e não apenas os juízos morais e políticos; (iv) nossa experiência total durante a vida influencia a forma como avaliamos uma prova e os valores morais e políticos; (v) existem conflitos básicos entre valores de forma que parece haver razões normativas para várias ações incompatíveis, entetanto, deve-se decidir; (vi) instituições sociais precisam selecionar alguns valores políticos e morais e estabelecer sua prioridade (RAWLS, 1999, p. 476-477).
} 
uma política de Estado mínimo. Para Brennan, penso, haveria evidências neutras que deveriam ser acessadas pelo experto para fundamentar sua decisão. Para Rawls, ao contrário, essas evidências podem ser interpretadas de maneira diversa, a partir das diferentes experiências de vida dos agentes. Por exemplo, ser negro ou mulher e ter enfrentado atos racistas e sexistas ao longo da vida, pode influenciar decisivamente um agente na forma de interpretar as evidências e os valores envolvidos para defender uma certa ação afirmativa, como um sistema de cotas. Pode não ser igual se imaginarmos um agente que nunca sofreu preconceitos. O problema da política, assim, não seria só de ignorância e irracionalidade, mas de perspectiva.

O domínio do politico seria, então, compreendido mais adequadamente não como um espaço de fatos neutros, que seria decidido pelo sábio, mas como um espaço público em que convivem pessoas que professam diferentes doutrinas religiosas, morais, econômicas etc. e que têm posições distintas e algumas vezes até antagônicas sobre como resolver os problemas da sociedade. Por isso, seria muito importante garantir as liberdades e os direitos básicos, sobretudo, os direitos políticos de votar e concorrer a cargos. Se no final das contas, a decisão será dada pela regra da maioria, seria temerário restringir os direitos políticos apenas de certos cidadãos a partir de um critério um tanto arbitrário como ignorância, assim como proposto por Brennan, uma vez que poderia ser o caso de simples diversidade de opiniões.

\section{IV}

A partir desta problematização do conhecimento/ignorância e do domínio político, nosso próximo passo será refletir sobre as virtudes públicas de prudência e amizade cívica, sobretudo, investigando o seu processo de aquisição. E isto é relevante, pois, para Brennan, a participação política favoreceria a estupidez e a inimizade cívica. Vejamos.

Para Brennan, a participação política tende a corromper-nos, ao invés de melhorar o nosso caráter intelectual e moral e torna-nos inimigos uns dos outros. Ele inicia o primeiro capítulo de Against Democracy fazendo uma contraposição entre Mill e Schumpeter. Diz que Mill defendia que o envolvimento político faria os cidadãos mais inteligentes, preocupados com o bem comum, melhor educados e nobres, fazendo com 
que as pessoas adotassem uma perspectiva de maior alcance, deixando de só pensar nos seus interesses imediatos. Por sua vez, para Schumpeter, o cidadão típico tem uma performance mental baixa no campo político, tendo por foco apenas o seu interesse, tornando-se primitivo novamente com a participação política. Diz, também, que na situação presente em que vivemos, a maioria das formas comuns de engajamento político não apenas falha em tornar as pessoas mais educadas ou virtuosas, mas, também, tende a tornar as pessoas estúpidas e corruptas. Como elas não se preocupam com a política, sendo, inclusive ignorantes sobre certos temas, quando não absolutamente irracionais, a saída não seria aumentar a participação política, mas restringi-la (BRENNAN, 2017, p. 1-3). No último capítulo, conclui a obra dizendo que a política tende a fazer-nos odiar uns aos outros e ver os membros do grupo adversário como inimigos, não favorecendo a amizade cívica (BRENNAN, 2017, p. 231-232).

$\mathrm{O}$ argumento de Brennan parece concluir que devemos nos afastar da política porque ela tanto favorece a estupidez, irracionalidade e ignorância, bem como ela nos torna inimigos uns dos outros e, como não se pode ter estabilidade social sem amizade cívica, o que significa os concidadãos se "verem engajados em um empreendimento cooperativo para vantagem mútua", devemos evitar "a política tanto quanto possível" (BRENNAN, 2017, p. 234-235). Esse argumento parece estar relacionado tanto com a concepção de Brennan de conhecimento político como de tudo ou nada, bem como relacionado a sua concepção de política como jogo de soma zero. Mas, como vimos, se tomarmos o conhecimento como expressão de certas virtudes intelectuais que se adquire com o hábito, através de exercícios repetidos, e se tomarmos a política não como apenas reduzida às disputas eleitorais, mas como uma possibilidade de se alcançar consensos normativos básicos, então, tanto o conhecimento político, que pode ser visto como prudência (sabedoria prática), como a amizade cívica, só serão possíveis com o engajamento político e não com a sua restrição, uma vez que não se pode adquirir nenhuma virtude sem exercício e que as virtudes públicas só podem ser adquiridas na própria esfera política. É difícil imaginar um cenário em que virtudes públicas, tal como a justiça ou a tolerância, por exemplo, seriam desenvolvidas exclusivamente na esfera privada.

Ao invés de tomarmos Schumpeter como referência, partimos do argumento educacional de Mill, como apresentado em Considerations on Representative Government, como forma de compreender como o engajamento político pode 
desenvolver as virtudes tanto morais como intelectuais dos agentes. Mill considera que a atividade política e civil requer que os cidadãos julguem a partir de uma visão imparcial dos interesses dos outros e busquem o bem-comum. Isto requer um pensamento de longa duração, bem como o engajamento em questões morais e de ciência social. Se for isso, então, a atividade política tenderá a aumentar as virtudes cívicas e tornar os cidadãos melhor informados. $\mathrm{O}$ argumento de Mill destaca que o engajamento político desenvolveria as habilidades de pensamento crítico dos cidadãos e aumentaria seu conhecimento. Defende corretamente que o envolvimento em política levaria os cidadãos a ter uma perspectiva mais imparcial dos problemas, os levando a ter maior empatia com os concidadãos e desenvolver uma forte preocupação com o bem-comum (MILL, 1975, p. 196-197).

O problema levantado por Brennan com o argumento educacional de Mill é que ele precisaria apresentar dados empíricos de que a participação política de fato enobrece e educa os agentes. E a partir de dados sociológicos negativos sobre a democracia deliberativa e dados psicológicos dos vieses cognitivos, Brennan conclui que o argumento educacional não é sólido e, por isso, devemos evitar a participação política (BRENNAN, 2017, p. 60-73). O problema é que esta abordagem está pretendendo dizer como é a natureza humana e a natureza das relações sociais e que elas seriam inalteráveis, o que revela uma visão um tanto essencialista. Por isso é interessante refletir sobre a especificidade das virtudes, que podem ser vistas como uma segunda natureza, uma vez que elas são adquiridas pelo hábito. No que segue, abordaremos as virtudes públicas da prudência e da amizade cívica que precisarão do engajamento político para sua aquisição. Para tal, parto de uma definição destas virtudes e procuro analisar sua importância. Por fim, reflito sobre o processo de sua aquisição.

A prudência (phronesis) é definida classicamente como uma disposição para encontrar os meios mais adequados para realizar um fim bom. Ela é vista como uma capacidade de deliberar bem sobre o que contribui para a vida boa. Isto implica em estar relacionada com uma capacidade de apreender os fins que são bons e, mais especificamente, a uma capacidade deliberativa para chegar a um resultado bemsucedido, escolhendo os meios mais eficientes para a realização do fim ${ }^{6}$. É uma virtude

\footnotetext{
${ }^{6}$ Para Aristóteles, a phronesis é uma capacidade verdadeira e raciocinada de agir com respeito às coisas que são boas ou más para os agentes. Em suas palavras: "A prudência (phronesis) é a disposição da
} 
que parece essencial para a política, uma vez que esta atividade, em geral, implica dentificar os meios necessários para alcançar um fim. Imaginando que o fim de um Estado seja alcançar a prosperidade econômica dos seus cidadãos, bem como garantir a sua segurança, não seria prudente adotar uma política econômica que excluísse a maior parte dos agentes de certos bens como educação, saúde e emprego, por exemplo. Um político prudente poderia identificar mais facilmente que uma política de bem-estar social seria mais adequada para o fim almejado. Não é à toa que Aristóteles considera como um paradigma de agente prudente Péricles, um político grego que foi muito importante para assegurar tanto a prosperidade como a paz em Atenas, em razão de sua capacidade de identificar o bem-comum, sendo esta uma capacidade fundamental para governar bem (ARISTOTLE, 1999, 1140b1-2).

A sua importância do ponto de vista público estaria ligada, em primeiro lugar, com a capacidade de identificação dos meios adequados para se chegar ao fim bom como já referido. Muitos desejam a paz e a prosperidade econômica, mas nem todos conseguem identificar os meios mais adequados para realizar esse fim, isto é, identificar as políticas públicas mais eficientes. Dessa forma, esta seria uma virtude central para um agente público, tal como um legislador ou membro do executivo. Além dessa perspectiva, penso que a prudência é também muito importante para os cidadãos em geral. $E$ isso porque o agente prudente poderia assumir mais facilmente as suas responsabilidades para com os outros, de forma a levar em conta as consequências de seus atos, assumindo mais facilmente os seus deveres de civilidade, tal como respeitar as leis de trânsito, seguir as normas sociais, jurídicas e políticas, bem como atribuir o mesmo peso aos interesses de todos, demostrando bom julgamento para decidir pelo bem-estar dos concidadãos.

A amizade cívica (politike philia), por sua vez, é uma virtude pública fundamental para garantir a unidade das sociedades e auxiliar no seu cuidado. É uma disposição que implica em uma preocupação mútua em relação ao caráter virtuoso dos cidadãos, isto é, significa desejar o bem do outro pelo próprio bem do outro. Como bem dito por Aristóteles, na Política, a amizade cívica é uma aspiração comum em relação a um padrão e excelência para todos os concidadãos (ARISTOTLE, 1995, 1295b1-3). Diferentemente da amizade pessoal, o conhecimento íntimo e a proximidade emocional

mente que se ocupa das coisas justas, corretas e boas para o ser humano, sendo essas as coisas cuja prática é característica de um homem bom (virtuoso)" (Aristotle, 1999, 1143b21-25). 
não estão presentes. Com isso, os traços comportamentais são expressos no reconhecimento de normas sociais no que diz respeito ao como devemos tratar as pessoas, isto significando conhecer a natureza da Constituição e suas qualidades, o nível de apoio entre a população no que é publicamente esperado do agente em sociedade, o que são os seus deveres comuns, entre outros. Como bem dito por Schwarzenbach, diferentemente da amizade pessoal, a amizade cívica se realiza em um processo de educação pública? .

A partir desta definição de amizade cívica fica mais claro ver qual seria sua importância. Ela pode ser tomada como condição necessária para a justiça em uma sociedade, uma vez que sem amizade cívica dificilmente se obterá a estabilidade social. $E$ isso porque mesmo que uma sociedade tenha regras de justiça, que garantem a liberdade, igualdade, dignidade dos cidadãos, sem essa disposição para desejar o bem dos outros, compartilhar valores, objetivos e um senso de justiça, dificilmente os agentes seguirão estas regras de justiça que possibilitariam uma vida em comum. Isso parece relevante mesmo quando pensamos em um estado liberal contemporâneo, que faz a distinção entre esfera privada e pública. Até mesmo Rawls, em sua teoria da justiça como equidade, vê como condição necessária que os cidadãos tenham certas virtudes políticas, como a disposição para honrar o dever de civilidade, para assegurar a estabilidade social pelas razões corretas, sendo estas virtudes tomadas como um capital político fundamental da sociedade, dependendo tanto da força das instituições sociais como do desempenho dos cidadãos em sua vivência pública (RAWLS, 2001, p. 115$119)^{8}$.

Agora, a questão mais relevante é refletir sobre o processo de aquisição destas virtudes públicas de prudência e amizade cívica. Como vimos brevemente, adquirimos as virtudes por um processo de habituação, em que exercícios repetidos formam o caráter do agente, o revestindo de uma segunda natureza. Nem a coragem,

\footnotetext{
7 No artigo "On Civic Friendship", Sibyl Schwarzenbach esclarece que em uma sociedade justa, os cidadãos experenciam uma forma de amizade entre si que se diferencia da amizade pessoal; eles desejam o bem dos outros, fazem coisas importantes para os concidadãos e compartilham valores, objetivos e um senso de justiça que os possibilita uma vida comum. E defende a possibilidade da amizade cívica em um Estado liberal, o que não se confunde com a pretensa comunidade platônica onde todas as coisas seriam compartilhadas, preservando a autonomia e a privacidade. Ver Schwarzenbach, 1996, p. 122-123.

8 Para Rawls, os valores políticos da razão pública refletem um ideal de cidadania, que é a nossa disposição para tratar das questões políticas fundamentais considerando os cidadãos como livres e iguais, racionais e razoáveis e este ideal nos conduz ao dever de civilidade pública, que nos direciona às questões constitucionais essenciais e questões básicas de justiça a partir de uma limitação pelo princípio da legitimidade. Ver Rawls, 2001, p. 91-92.
} 
moderação ou generosidade são traços de caráter naturais. Eles são adquiridos por um processo de afastamento dos extremos. Por exemplo, na coragem, do afastamento em relação à temeridade, que é o subestimar os perigos, e a covardia, que é superestimálos. Esse processo se inicia com a disposição do agente, a partir de sua aspiração em ser melhor, é certo, mas há um importante papel social, e isto porque as virtudes são critérios normativos socialmente mediados. É o grupo em uma sociedade que elogia um certo tipo de comportamento e censura outro. Por exemplo, elogia geralmente atos corajosos, moderados, generosos e justos e censura em geral atos covardes, intemperantes, egoístas e injustos. Assim, podemos dizer que adquirir virtudes é um empreendimento coletivo.

Com isso em mente, não é difícil imaginar que o processo de aquisição das virtudes se dará no campo educacional, tanto na educação familiar como no da educação escolar. Além do processo educativo, podemos apontar, também, para o importante papel das instituições políticas e jurídicas. As virtudes dos cidadãos em muito são devedoras das virtudes das instituições públicas de uma sociedade. Sendo elas justas, por exemplo, existirá uma grande possibilidade dos agentes também se tornarem justos. Agora, e a participação política? Ela teria alguma relevância na aquisição destas virtudes em tela? Penso que sim. Tomando a política como não reduzida a uma disputa eleitoral, em que teríamos sempre um ganhador e um perdedor, podemos considerar que o engajamento político favorecerá a aquisição tanto da prudência como da amizade cívica. Vejamos.

Imaginem uma assembleia constituinte. Nela, os cidadãos votam para eleger os legisladores constituintes que terão a tarefa de realizar a Constituição. Depois de eleitos, estes constituintes ouvem parcelas significativas da sociedade, como empresários, professores, comerciantes, agricultores, pecuaristas, sem-teto, sem-terra, ecologistas, grupos LGBT etc. A partir destas consultas e trabalhando em comissões vão apresentando o texto como está sendo formulado. Ele sofre críticas de uns, pressões de outros, elogios de muitos e, por fim, a Constituição é promulgada. A participação nesse processo constituinte, penso, favorece o surgimento de amizade cívica, uma vez que o texto que será a referência normativa política central para aquela sociedade teve o envolvimento de todos. Imaginem se um determinado grupo fosse impedido de participar deste processo constituinte, talvez pela razão de ser ignorante e irracional. Como o grupo se sentiria? Provavelmente esta restrição geraria ressentimento ou até 
mesmo raiva contra aqueles que o impediram de participar. Essa situação de assimetria provavelmente seria determinante para uma baixa autoestima. Mas, fundamentalmente, essa restrição poderia criar uma inimizade cívica.

Vejamos um outro exemplo. Imaginem uma sociedade epistocrática em que os cidadãos não elegem os legisladores e membros do executivo, da mesma forma que em sociedades democráticas não elegemos os juízes, e considerando que estas autoridades públicas têm as mesmas funções que em democracias contemporâneas, isto é, fazer as leis, executar e julgar, mas ao invés de serem eleitos, eles são selecionados por concurso. Mesmo considerando que estas autoridades sejam competentes para garantir o bem-estar de todos, provavelmente os cidadãos teriam bastante dificuldade em reconhecer os seus deveres comuns, isto é, a sua reponsabilidade política e social, como não fazer ações que coloquem o outro em perigo. Como adquirir a virtude da prudência, isto é, da sabedoria prática, estando alheio ao engajamento político? Como a prudência tem uma característica muito peculiar, sendo uma virtude intelectual, mas que é condição de possibilidade tanto para as outras virtudes intelectuais como para as virtudes morais, parece que ela só será cultivada plenamente no domínio público, não sendo suficiente para o seu total florescimento o domínio privado. Será que se Péricles não tivesse podido se engajar politicamente ele teria se tornado um exemplo de agente prudente, isto é, como aquele que tanto consegue identificar o fim bom como conhece os meios adequados para sua realização, pensando especialmente no bem comum? Creio que dificilmente ${ }^{9}$.

\section{V}

Vimos até agora que o argumento epistocrático condicional de Brennan, que propõe restringir o voto dos cidadãos irracionais e ignorantes em política, tem por base uma compreensão tradicional do conhecimento, isto é, como sendo sinônimo de crença verdadeira justificada e ignorância como equivalente a ter crenças falsas, que seriam crenças não amparadas por evidências adequadas, bem como um entendimento de

\footnotetext{
${ }^{9}$ Tholen diz acertadamente que a responsabilidade política pode ser vista como uma virtude, significando que ela pode ser apreendida e adquirida pelos agentes. Diz, também, que a verdadeira prática política é aquela realizada pelo bom político, isto é, pelo político virtuoso. E um bom político é aquele que é reconhecido como o que sabe lidar melhor com os conflitos típicos da política. Ver Tholen, 2018, p. 31.
} 
política como jogo de soma zero, em que a vitória de uns implicaria necessariamente a derrota de outros, tomando os cidadãos como agentes que decidem de forma emocional e a partir da perspectiva de seu próprio grupo, isto é, tribalisticamente. Nessa última seção do texto, quero destacar e me contrapor a um certo essencialismo que parece pressuposto na concepção de Brennan, uma vez que ele estaria tomando a natureza humana como egoísta e irracional e as relações sociais mediadas apenas pelo autointeresse, as vendo como imutáveis e, por isso, a conclusão lógica seria diminuir a participação política e não aumentá-la. Para tomar uma expressão de Buchanan, Brennan estaria assumindo o "dogma do tribalismo", uma vez que parece defender a tese de que a natureza moral dos seres humanos é tribalística (BUCHANAN, 2020, p. xv; 6-8). Mas, seria correto ver a natureza humana como imutável? Não estaria mais de acordo com as descobertas recentes da neurociência ver as capacidades mentais humanas, especialmente as morais, como plásticas, isto é, como flexíveis e adaptáveis, que comportam tanto o tribalismo como a moralidade inclusiva, isto é, um altruísmo expandido para os membros de outros grupos?

Com isso em mente, deixem-me fazer referência ao fenômeno do progresso moral e isso para evidenciar que, embora o tribalismo esteja presente em nossas decisões, sobretudo as políticas, de um ponto de vista histórico, atualmente somos menos tribalistas do que já fomos no passado, isto significando uma maior inclusividade no círculo de proteção moral ou uma "expansão no círculo da ética" ou, ainda, uma "moralidade inclusivista"10. O progresso moral, assim, pode ser tomado como uma evidência de que embora os vieses cognitivos sejam uma realidade em nossas práticas decisórias, eles não impossibilitaram o processo de inclusão de certos agentes no grupo, garantindo o mesmo status moral para uma classe de indivíduos que eram previamente excluídos, como os outros povos, os membros de outras etnias, de outro gênero, além dos animais não-humanos e até mesmo a natureza. Outra forma de ver a

\footnotetext{
${ }^{10} \mathrm{O}$ fenômeno pode ser tomado como uma maior inclusão no ć́rculo moral. No passado, considerando as sociedades de caçadores-coletores, a proteção de cuidado e reciprocidade estava restrita aos membros de um pequeno grupo, de forma que só os seus estariam protegidos da agressão, enquanto os outros agentes não eram considerados como iguais e, mais, constituíam uma ameaça. $E$ internamente, havia arbitrariedade em relação a certos integrantes, como no caso da discriminação às mulheres. Com o decorrer do tempo, passou-se a incluir na preocupação ética os outros povos, pessoas de outras etnias, mulheres, animais não-humanos e até mesmo a natureza. Em outras palavras, o progresso moral é a saída do tribalismo em direção a uma maior inclusividade normativa-ética. Singer, por exemplo, explica o fenômeno como uma "expansão do círculo da ética", enquanto Buchanan e Powell o compreendem como uma "moralidade inclusivista". Ver Singer, 2011, p. 111-124. Ver, também, Buchanan; Powell, 2018, p. 62-66.
} 
questão é reconhecer que o progresso moral é uma evidência de que o conhecimento político, embora difícil, é possível, mas que ele deve ser interpretado em uma perspectiva progressiva. Por exemplo, no passado tanto a instituição da escravidão como as práticas sexistas eram tomadas como normais e vistas como corretas moralmente. Hoje elas são consideradas injustas e são fortemente censuradas pelo conjunto da sociedade. Mas, vejamos mais detalhadamente um exemplo paradigmático deste tipo de progresso, a saber, o reconhecimento universal dos direitos humanos.

Logo após o término da Segunda Guerra Mundial, a Declaração Universal dos Direitos Humanos foi elaborada por representantes de diferentes realidades jurídicas e culturais de todas as regiões do mundo e foi proclamada pela Assembleia Geral das Nações Unidas em 10 de dezembro de 1948, instituindo uma proteção normativa a todos os membros da espécie humana. Diz no seu Preâmbulo que se deve reconhecer que a "(...) dignidade inerente a todos os membros da família humana e de seus direitos iguais inalienáveis é o fundamento da liberdade, da justiça e da paz no mundo". Também, que é fundamental "(...) promover o desenvolvimento de relações amistosas entre as nações" e afirmar a "(...) fé nos direitos humanos fundamentais, na dignidade do ser humano e na igualdade de direitos entre homens e mulheres". Os seus 30 artigos asseguram os direitos à vida, liberdade e segurança para todos os seres humanos, condenando a discriminação racial, de gênero, de religião ou mesmo de algum posicionamento político. Garantem, também, a proteção contra a tortura, castigo cruel, escravidão, defendendo, igualmente, a igualdade de todos perante a lei e o direito ao asilo político, ao trabalho, à instrução e à saúde, entre outros direitos ${ }^{11}$.

Veja-se que até a criação da ONU e da proclamação da Declaração Universal o meio mais usual para resolução de conflitos entre as nações era a guerra, sendo que, inclusive, a tortura e ataques a civis eram meios usuais para se obter a vitória, bem como o nacionalismo e o patriotismo eram virtudes exaltadas em todos os continentes. Inclusive, se olharmos para a antiguidade, veremos que até a escravidão era legitimada em razão de uma derrota bélica. Do ponto de vista econômico e político, o colonialismo e o imperialismo eram naturalizados até pouco tempo atrás. $E$ do ponto de vista dos direitos civis, não era estranho depararmo-nos com regimes de segregacionismo racial, tal como na África do Sul e nos Estados Unidos da América. Após esse período,

11 Ver a Declaração Universal dos Direitos Humanos (Universal Declaration of Human Rights) em https://www.un.org/en/universal-declaration-human-rights/. Acesso em 05 de agosto de 2020. 
iniciamos um processo de ampliação do círculo moral e político, de forma a garantir aos excluídos uma proteção normativa. Torturas e castigos físicos cruéis foram banidos das práticas na maior parte dos países, bem como o nacionalismo e patriotismo passaram a enfrentar oposição de demandas cosmopolitas. Não existem mais impérios coloniais e o imperialismo é fortemente censurado em termos planetários, bem como políticas segregacionistas não são mais habituais.

Dito isto, é importante reconhecer que o ambiente social e político deste tipo de progresso normativo exemplificado pelo reconhecimento planetário dos direitos humanos foi o das democracias representativas liberais que se caracterizam pela descentralização do poder político e, mais especificamente, por uma limitação do poder dos governantes em relação aos direitos dos cidadãos, isto implicando o respeito às diversas demandas de grupos da sociedade civil, garantindo autonomia do indivíduo e da sociedade. Veja-se que sem as garantias de liberdade de expressão e de associação dificilmente a escravidão teria sido abolida, bem como dificilmente as mulheres teriam conquistado o direito ao voto. Também, que sem uma ordem hierárquica múltipla, com separação dos poderes e, em especial, independência do judiciário, provavelmente o segregacionismo racial não teria terminado. Até o direito à propriedade privada e a instituição do livre mercado com justiça social parecem ter auxiliado na mobilidade social e na maior inclusão econômica dos desfavorecidos. Mas, mais importante, sem uma ordem democrática, em que se parte do pressuposto que as diversas demandas da sociedade civil são legítimas, dificilmente os homossexuais teriam conquistado uma condição de igualdade com os outros cidadãos, igualdade que hoje lhes protege da punição, uma vez que em muitos países a homossexualidade era crime, e lhes garante o direito ao casamento ou união civil e a adoção de crianças. Pode-se dizer que as democracias representativas liberais são condição de possiblidade do progresso moral $^{12}$.

O ponto que quero chamar atenção é que o "tribalismo" não impediu essa maior inclusividade normativa, de forma a se ver uma exigência do altruísmo tanto nas

\footnotetext{
12 Allen Buchanan também defende que a ordem liberal-democrática pode ser tomada como uma condição necessária para o progresso moral em larga escala. Ele destaca o papel vital que as instituições desempenham para se alcançar este progresso, destacando a defesa da liberdade de expressão, religiosa, de associação, bem como o poder descentralizado. Inclusive, ele defende a hipótese que o "contexto epistêmico social" foi uma condição necessária para o progresso moral, contexto caracterizado pela: (i) disseminação de ideias através dos livros, (ii) liberdade de expressão e associação, (iii) reconhecimento da diversidade cultural, (iv) cultura de apresentar razões ou justificações, (v) práticas de tolerância e (vi) direitos assegurados aos inovadores morais. Ver Buchanan, 2020, p. 146-151.
} 
relações entre as nações, bem como entre os diferentes membros de uma mesma nação. Penso que o progresso moral, embora não linear nem necessário, pode ser compreendido como uma evidência da plasticidade de nossas capacidades morais deliberativas, que nos possibilita restringir progressivamente a arbitrariedade em nossos juízos morais e políticos em direção a um altruísmo expandido. Também, creio que este progresso pode ser interpretado como uma evidência de que o conhecimento político, embora complexo e não redutível a uma identificação neutra das evidências, é possível, sobretudo se ele for considerado não em uma perspectiva de tudo ou nada, mas como uma questão de graus, em que se alcança a sabedoria progressivamente. Dado que as democracias representativas se constituíram historicamente como o ambiente social hegemônico da expansão do círculo ético, penso que não temos uma razão conclusiva para defender uma restrição da participação política. Ao contrário, talvez devêssemos mesmo considerar que um aumento desta participação produzisse ainda mais bem-estar e justiça.

\section{Referências}

ANNAS, J. Intelligent Virtue. Oxford: Oxford University Press, 2011.

ARISTOTLE. Nicomachean Ethics. Transl. Terence Irwin. 2a. Ed. Indianapolis: Hackett, 1999.

Press, 1995.

Politics. Transl. Ernest Barker revised by Richard Stalley. Oxford: Oxford University

BRENNAN, J. Against Democracy. Princeton, New Jersey: Princeton University Press, 2017.

BUCHANAN, A. Our Moral Fate: Evolution and the Escape from Tribalism. Cambridge, MAS: The MIT Press, 2020.

BUChANAN, A.; POWELL, R. The Evolution of Moral Progress: A Biocultural Theory. New York: Oxford University Press, 2018.

CHISHOLM, R. Perceiving: A Philosophical Study. Ithaca, NY: Cornell University Press, 1957.

GETTIER, E. Is Justified True Belief Knowledge? Analysis, Vol. 23, No. 6, 1963, p. 121-123.

MILL, J. S. Three Essays: On Liberty, Representative Government, and The Subjection of Women. Edited by Richard Wollheim. New York: Oxford University Press, 1975.

NOZICK, R. The Examined Life: Philosophical Meditations. New York: Simon and Schuster, 1990.

PEELS, R. What is Ignorance? Philosophia, Vol. 38, 2010, p. 57-67. 
RAWLS, J. The Domain of the Political and Overlapping Consensus (1989). In: RAWLS, John. Collected Papers. Edited by Samuel Freeman. Cambridge, MAS: Harvard University Press, 1999, p. 473-496.

Justice as Fairness: $A$ Restatement. Edited by Erin Kelly. Cambridge, MAS: Harvard University Press, 2001.

SCHWARZENBACH, S. A. On Civic Friendship. Ethics, Vol. 107, No. 1, 1996, p. 97-128.

SINGER, P. The Expanding Circle: Ethics, Evolution, and Moral Progress. Princeton: Princeton University Press, 2011.

SOSA, E. A Virtue Epistemology: Apt Belief and Reflective Knowledge, Vol. I. Oxford: Clarendon Press, 2007.

THOLEN, B. Political Responsibility as Virtue: Nussbaum, Maclntyre, and Ricoeur on the Fragility of Politics. Alternatives: Global, Local, Political, Vol. 43, No. 1, 2018, p. 22-34.

UNITED NATIONS. Universal Declaration of Human Rights (UDHR), 1948. Disponível em https://www.un.org/en/universal-declaration-human-rights/. Acesso em 05 de agosto de 2020. 